\title{
Kemampuan Pemahaman Konsep Matematika Siswa Melalui Pendekatan Pendidikan Matematika Realistik Indonesia (PMRI) pada Pembelajaran Matematika di Kelas VIII SMP PGRI 1 Betung
}

\author{
Muhammad Yogi Ramadhan ${ }^{1}$, Eka Yanuarti \\ ${ }^{1}$ Institut Agama Islam Negeri Curup \\ 1yogi.wirono90@gmail.com
}

\begin{tabular}{l}
\hline \hline Article Info \\
\hline Article history: \\
Received Dec $31^{\text {th }}, 2020$ \\
Revised Dec $31^{\text {th }}, 2020$ \\
Accepted Dec $31^{\text {th }}, 2020$ \\
\hline
\end{tabular}

Keywords:

Mathematical

Understanding

Concepts;

PMRI

\begin{abstract}
This study aims to determine the ability to understand students' mathematical concepts through the Indonesian Realistic Mathematics Education (PMRI) Approach to Mathematics Learning in Class VIII of SMP PGRI 1 Betung. This research is a "quasi experiment" category of one shot case study. In this study, there was only one sample class, namely the class that became the experimental class, namely class VIII.5 consisting of 35 students, which was carried out without a control class or comparison class. The data collection techniques used in this study are the test method and documentation. The results of this study indicate that the students' ability to understand mathematical concepts after the application of the Indonesian Realistic Mathematics Education Approach (PMRI) at SMP PGRI Betung is categorized as good, this is shown by the results of the average score. -The average final test of students' ability to understand mathematical concepts was 76.8 .
\end{abstract}

Kata Kunci:

Pemahaman Konsep Matematika;

PMRI

Abstrak
Penelitian ini bertujuan untuk mengetahui Kemampuan
Pemahaman Konsep Matematika Siswa Melalui
Pendekatan Pendidikan Matematika Realistik Indonesia
(PMRI) pada Pembelajaran Matematika Di Kelas VIII
SMP PGRI 1 Betung. Penelitian ini merupakan "quasi
experiment" kategori one shot case study. Dalam
penelitian ini hanya ada satu kelas sampel yaitu kelas
yang menjadi kelas eksperimen yaitu kelas VIII.5 yang
terdiri atas 35 orang siswa yang dilaksanakan tanpa
kelas control atau kelas perbandingan. Teknik
pengumpulan data yang digunakan penelitian ini adalah
metode tes, dan dokumentasi. Hasil penelitian ini
menunjukkan bahwa kemampuan pemahaman konsep 
matematika siswa setelah diterapkannya Pendekatan Pendidikan Matematika Realistik Indonesia ( PMRI) di SMP PGRI Betung dikategorikan baik, hal ini ditunjukkan dengan hasil nilai rata-rata tes akhir kemampuan pemahaman konsep matematika siswa adalah 76,8 .

\section{PENDAHULUAN}

Matematika sering dipandang oleh siswa sebagai mata pelajaran yang menakutkan. Siswa mengalami kesulitan dalam memecahkan masalah matematika. Selain itu, motivasi belajar matematika juga rendah. Akibatnya prestasi belajar matematika siswa kurang menggembirakan (Widada et al., 2019:1). Matematika sendiri adalah aktivitas manusia, oleh karena itu objek matematika dalam pembelajaran matematika harus dimulai dengan masalah nyata dalam kehidupan sehari-hari atau yang dekat dengan pikiran siswa (Widada, Herawaty, \& Lubis, 2018:1). Sehingga dalam hal ini dunia pendidikan merupakan sarana yang sangat berperan dalam mendidik manusia untuk menjadi manusia-manusia yang memiliki prestasi dalam berbagai ilmu untuk mengisi pembangunan bangsa (Yanuarti, 2016c:90). Pendidikan memegang peranan penting dalam kehidupan karena pendidikan merupakan wahana untuk meningkatkan dan mengembangkan kualitas sumber daya manusia (SDM) (Yanuarti, 2016a:613). Sebagaimana pengertiannya bahwa pendidikan merupakan bentuk usaha sadar dan terencana yang berfungsi untuk mengembangkan potensi yang ada pada manusia agar bisa digunakan untuk kesempurnaan hidupnya di masa depan nanti (Yanuarti, 2016b:146). Pemerintah merumuskan dalam Undang-Undang Republik Indonesia No. 20 tahun 2003 tentang Sistem Pendidikan Nasional yang menjelaskan bahwa pendidikan dilakukan agar mendapatkan tujuan yang diharapkan bersama yaitu: "Pendidikan nasional berfungsi mengembangkan kemampuan dan membentuk watak serta peradaban bangsa yang bermartabat dalam rangka mencerdaskan kehidupan bangsa, bertujuan untuk berkembangnya potensi peserta didik agar menjadi manusia yang beriman dan bertakwa kepada Tuhan Yang Maha Esa, 
berakhlak mulia, sehat, berilmu, cakap, kreatif, mandiri, dan menjadi warga negara yang demokratis serta bertanggung jawab" (Yanuarti, 2018: 239).

Pelajaran matematika merupakan salah satu pelajaran penting karena materi yang dipelajari berguna untuk kehidupan sehari-hari. Apalagi di zaman yang sudah secanggih saat ini, siswa dituntut untuk mampu menguasai bidang ilmu matematika. Matematika merupakan salah satu bidang studi pendukung sistem pendidikan nasional dalam rangka meningkatkan kualitas sumber daya manusia dan matematika juga menduduki peranan penting dalam dunia pendidikan karena matematika merupakan salah satu mata pelajaran yang diajarkan di sekolah-sekolah dengan frekuensi jam pelajaran yang lebih banyak dari jam pelajaran pada mata pelajaran yang lain dan marupakan salah satu mata pelajaran yang wajib diberikan di setiap jenjang pendidikan mulai dari pendidikan dasar sampai perguruan tinggi. Dalam memahami pembelajaran matematika setiap materi yang diajarkan guru penting untuk dimiliki oleh setiap siswa karena membantu proses mengingat dalam mengerjakan soal matematika yang membutuhkan banyak rumus (Ma'Rifah, Widada, Aida, Yulfitri, \& Effendi, 2019:65).

Berdasarkan Peraturan Menteri Pendidikan Nasional No 23 Tahun 2006 tentang Standar Kompetensi Lulusan (SKL) untuk Sekolah Menengah Pertama (SMP)/Madrasah Tsanawiyah (MTs) pada mata pelajaran matematika, siswa mampu diantaranya adalah: 1) memahami konsep bilangan real, operasi hitung dan sifat-sifatnya, barisan bilangan sederhana, serta penggunaannya dalam pemecahan masalah; 2) memahami konsep aljabar; 3) memahami bangun-bangun geometri, unsur-unsur dan sifat-sifatnya, ukuran dan pengukurannya; 4) memahami konsep ruang sampel dan peluang kejadian, serta memanfaatkan dalam pemecahan masalah (KTSP, 2008:273).

Kurikulum Tingkat satuan Pendidikan (KTSP) sebagai hasil pembaharuan Kurikulum Berbasis Kompetensi (KBK) juga menghendaki bahwa suatu pembelajaran pada dasarnya tidak hanya mempelajari tentang konsep, teori dan fakta tapi juga aplikasi dalam kehidupan seharihari(Trianto, 2010:3). 
Menurut Trianto, kenyataan di lapangan siswa hanya menghafal konsep dan kurang mampu menggunakan konsep tersebut jika menemui masalah dalam kehidupan nyata yang berhubungan dengan konsep yang dimiliki lebih jauh lagi bahkan siswa kurang mampu menentukan masalah dan merumuskannya (Trianto, 2010:65).

Pemahaman konsep merupakan kompetensi yang ditunjukkan siswa dalam memahami konsep dan dalam melakukan prosedur (algoritma) secara luwes, akurat, efisien dan tepat (Yustisia, 2010: 429) dan menurut Trianto pemahaman konsep dalam proses belajar mengajar sangat mempengaruhi sikap, keputusan, dan cara-cara menyelesaikan masalah (Trianto, 2010:65). Pendekatan pembelajaran matematika realistik lebih rendah daripada siswa yang belajar dengan pembelajaran langsung. Pembelajaran etnomatematika dapat meningkatkan kemampuan pemahaman konsep (Nugroho, Widada, Zamzaili, \& Herawaty, 2019: 123). Memahami konsep matematika merupakan masalah bagi siswa. Ketika siswa harus menentukan genus proksimal dan diferensiator spesifik. Selain itu, bagaimana membedakan antara memahami tindakan dan proses dan saat menghubungkan "pemahaman yang baik" dari situasi matematika (konsep, teori, masalah) dengan urutan tindakan mengatasi hambatan khusus untuk situasi ini (Suharto, 2018). Dalam meningkatkan pemahaman konseptual diperlukan dalam proses penguasaan konsep dalam matematika. Sebagaimana pengertian dari matematika itu sendiri yaitu refleksi dari dunia nyata, melalui proses abstraksi empiris. Artinya, pembelajaran matematika harus mengkondisikan kegiatan interaktif antar komponen pembelajaran (sumber belajar guru), memudahkan siswa dalam menyelesaikan tugasnya, dan menginternalisasikan konsep/prinsip matematika formal (Herawaty \& Widada, 2018:97). Objek matematika bersifat abstrak, termasuk konsep. Oleh karena itu, pembelajaran matematika merupakan pembelajaran tentang materi abstrak, sehingga siswa mengalami kesulitan dalam mempelajarinya. Guru harus menemukan pendekatan yang tepat untuk mengajarkannya. Kemudahan belajar dapat dirasakan jika isi dan konteks pembelajaran berkaitan dengan aktivitas siswa sehari-hari. Salah satunya adalah pendekatan 
pembelajaran yang bersifat realistik (Herawaty, Widada, Nugroho, \& Anggoro, 2019: 21).

Berdasarkan observasi awal peneliti dalam pembelajaran Matematika di SMP PGRI I Betung didapati bahwa pembelajaran di sana masih dominan menggunakan pendekatan konvensional yaitu metode ceramah. Sehingga pemahaman konsep siswa masih rendah, dimana siswa hanya menghafal konsep, kurang mampu menggunakan konsep tersebut untuk memecahkan masalah dalam kehidupan nyata yang berhubungan dengan konsep yang dimilikinya dan masih mengalami kesulitan dalam menyatakan ulang maksud dari konsep dan mengaplikasikan konsep ke dalam pemecahan masalah.

Dari uraian di atas, maka sudah selayaknya kemampuan pemahaman konsep matematis mendapatkan perhatian yang sangat khusus dalam pembelajaran matematika apabila kelemahan semacam ini tidak diantisipasi dan diperbaiki, maka akan menghambat pencapaian tujuan pembelajaran matematika. Untuk itu diperlukan pendekatan alternatif yang diharapkan dapat digunakan dalam mengatasi rendahnya pemahaman konsep yang dimiliki siswa.

Salah satu pendekatan yang dapat digunakan dalam mengatasi rendahnya pemahaman konsep yang dimiliki siswa adalah penggunaan teori Pendidikan Matematika Realistik Indonesia (PMRI). PMRI diadopsi dari Realistic Mathematics Education (RME). PMRI adalah teori pembelajaran yang bertitik tolak dari hal-hal yang real bagi siswa. Menekankan kepada kemampuan siswa berdiskusi, dan berkalobarasi, berargumentasi dengan teman sekelas sehingga mereka dapat menemukan sendiri dan pada akhirnya menggunakan matematika untuk menyelesaikan masalah baik secara individu maupun kelompok. Dalam PMRI, peran guru sebagai fasilitator, moderator atau evaluator sementara siswa berpikir, mengkomunikasikan, melatih nuansa demokrasi dengan menghargai pendapat dan pemahaman konsep orang lain.

\section{METODE PENELITIAN}

Metode yang digunakan dalam penelitian ini adalah metode eksperimen semu atau sering disebut juga "quasi experiment" kategori 
one shot case study. Dalam penelitian ini hanya ada satu kelas sampel yaitu kelas yang menjadi kelas eksperimen yaitu kelas VIII.5 yang terdiri atas 35 orang siswa yang dilaksanakan tanpa kelas kontrol atau kelas perbandingan. Teknik pengumpulan data yang digunakan penelitian ini adalah metode tes dan dokumentasi. Analisis uji coba instrumen dalam penelitian ini yaitu menggunakan uji validitas, uji reliabilitas, daya pembeda dan taraf kesukaran. Teknik analisis data berupa tes dalam penelitian ini menggunakan uji normalitas, uji homogenitas dan uji hipotesis.

\section{HASIL PENELITIAN DAN PEMBAHASAN}

Dalam penelitian ini, kemampuan pemahaman konsep siswa dapat dilihat dari hasil latihan/tes setiap akhir pertemuan dan tes akhir yang diberikan pada pertemuan keempat. Adapun data tes rata-rata kemampuan pemahaman konsep siswa setiap pertemuan dan tes akhir pada materi kubus dan balok sebanyak 3 kali pertemuan dan 1 kali tes akhir dapat dilihat pada tabel di bawah ini:

\section{Tabel 1 Nilai Rata-Rata Pemahaman Konsep Matematika Siswa}

\begin{tabular}{ccccc}
\hline Kelas & \multicolumn{3}{c}{ Pertemuan } & Rata-rata \\
\cline { 2 - 4 } & I & II & III & \\
\hline VIII.5 & 66 & 76 & 80,9 & 74,2 \\
\hline Kategori & Cukup & Baik & baik & baik \\
\hline
\end{tabular}

Dari Tabel 1, terlihat bahwa nilai tes rata-rata kemampuan pemahaman konsep siswa per individu setiap pertemuan mengalami peningkatan setelah diterapkannya PMRI. Nilai tes yang diikuti oleh 35 siswa dari 35 siswa pada pertemuan 1 adalah 66 dengan kategori cukup, pada tes pertemuan ke II yang diikuti oleh 35 siswa nilai tes rata-rata siswa adalah 76 dengan kategori baik, sedangkan pada tes pertemuan ke III yang diikuti 35 siswa nilai tes rata-rata siswa adalah 80,9 dengan kategari baik. Dari data di atas dapat dilihat bahwa rata-rata nilai siswa dari ketiga pertemuan adalah 74,2 dengan kategori baik. 
Tabel 2 Kemampuan Pemahaman Konsep Matematika Siswa Melalui Pembelajaran Pendekatan Matematika Realistik Indonesia (PMRI)

\begin{tabular}{cccc}
\hline $\begin{array}{c}\text { Tingkat } \\
\text { Penguasaan } \\
\text { Siswa }\end{array}$ & $\begin{array}{c}\text { Kategori } \\
\text { Pemahaman } \\
\text { Konsep Siswa }\end{array}$ & Frekuensi & Persentase \\
\hline $86-100 \%$ & Sangat Baik & 9 & $25,71 \%$ \\
\hline $71-85 \%$ & Baik & 14 & $40 \%$ \\
\hline $56-70 \%$ & Cukup & 9 & $25,71 \%$ \\
\hline $41-55 \%$ & Kurang & 2 & $5,71 \%$ \\
\hline$\leq 40$ & Kurang sekali & 1 & $2,85 \%$ \\
\hline Jumlah & & & $100 \%$ \\
\hline Rata-rata & Baik & & \\
\hline
\end{tabular}

Dari tabel di atas, terlihat bahwa data nilai tes akhir kemampuan pemahaman konsep siswa setelah diterapkannya PMRI pada pembelajaran matematika, materi kubus dan balok terdapat $25,71 \%$ siswa memperoleh nilai tes dengan kategori sangat baik, $40 \%$ siswa memperoleh nilai tes kategori baik, $25,71 \%$ siswa memperoleh nilai tes dengan kategori cukup, $5,71 \%$ siswa memperoleh nilai tes dengan kategori kurang, dan 2,85\% siswa memperoleh nilai tes dengan kategori sangat kurang. Dari data di atas dapat dilihat bahwa rata-rata nilai tes akhir siswa adalah 76,8 dengan kategori baik.

Secara keseluruhan kemampuan pemahaman konsep matematika siswa berdasarkan hasil tes setiap pertemuan dan tes akhir yang telah diuraikan di atas menunjukkan kategori nilai baik dengan demikian maka kemampuan pemahaman konsep matematika siswa melalui PMRI adalah baik.

Dari data tes di atas diketahui bahwa kemampuan pemahaman konsep matematika siswa SMP PGRI Betung kelas VIII.5 dengan menggunakan PMRI adalah baik.

Hal ini dapat dilihat pada pertemuan I kemampuan pemahaman konsep matematika siswa dengan rata-rata 66 . Hal ini dikarenakan siswa belum terbiasa belajar dengan menggunakan pembelajaran dalam bentuk kelompok, meski telah dibagi dalam kelompok, siswa masih belajar secara individu, sehingga diskusi kurang berjalan dengan baik dan siswa 
juga belum mampu menemukan solusi dalam memecahkan masalah sehari-hari dalam bentuk soal kelompok sehingga siswa kurang memahami materi.

Pada pertemuan II mulai terlihat mengalami peningkatan dimana kemampuan pemahaman konsep siswa dengan rata-rata 76. Pada pertemuan II ini peneliti berusaha memotivasi siswa untuk belajar dan berdiskusi secara kelompok, sehingga pada pertemuan II ini siswa sudah terlihat aktif berdiskusi tetapi pada pemecahan masalah sehari-hari dalam bentuk tugas kelompok masih perlu bimbingan dan bantuan peneliti sehingga kemudian dapat menyelesaikan masalah yang diberikan oleh peneliti.

Pada pertemuan III ini semua langkah-langkah PMRI telah dilaksanakan dengan baik oleh siswa sehingga siswa telah terbiasa berdiskusi dalam kelompok untuk memecahkan masalah matematika dalam kehidupan sehari-hari sehingga pada pertemuan III ini juga mengalami peningkatan dari pertemuan sebelumnya yaitu kemampuan pemahaman konsep matematika siswa dengan rata-rata 80,9. Dari hal tersebut terlihat bahwa dengan menggunakan PMRI pada pelajaran Matematika dapat meningkatkan kemampuan pemahaman konsep matematika siswa.

Dari hasil pertemuan pertama sampai dengan pertemuan ketiga di kelas yang menerapkan PMRI, seperti yang peneliti amati pada salah satu siswa yaitu Rani oktasari. Pada pertemuan pertama mendapat nilai 60 hal ini dikarenakan pada pertemuan pertama belum terbiasa menggunakan PMRI sehingga langkah-langkah dalam PMRI belum dapat diterapkan dengan baik sehingga kemampuan pemahaman konsep matematika siswa masih rendah. Pada pertemuan kedua hasil kemampuan pemahaman konsep matematika Rani mengalami peningkatan, Rani mendapat nilai 80 karena mendapatkan motivasi dari peneliti, Rani mulai menyukai cara belajar yang diterapkan peneliti, serta menyimak penjelasan dari peneliti dan pada pertemuan ketiga terjadi peningkatan yang cukup signifikan dari 80 pada pertemuan kedua menjadi 100, hal ini dikarenakan pada setiap pertemuan siswa sudah dapat menerapkan pendekatan PMRI dengan baik 
sehingga kemampuan pemahaman konsep matematika siswa semakin baik pada setiap pertemuan.

Dari hasil analisis dan tes, secara keseluruhan rata-rata kemampuan pemahaman konsep matematika siswa mengalami peningkatan, setelah dari hasil analisis tersebut terlihat bahwa PMRI dapat meningkatkan kemampuan pemahaman konsep siswa. Hasil temuan tersebut menunjukkan pula bahwa PMRI mengajak siswa untuk terlibat dalam kegiatan belajar mengajar sesuai dengan Karakteristik PMRI yang pada intinya adalah matematika merupakan aktivitas insani, pembelajaran matematika tidak dapat dipisahkan dari sifat matematika seseorang memecahkan masalah, mencari masalah dan mengorganisasi materi pelajaran, untuk itu pendidikan matematika harus diarahkan pada penggunaan berbagai situasi dan kesempatan yang memungkinkan siswa menemukan kembali matematika berdasarkan usaha mereka sendiri.

\section{SIMPULAN}

Berdasarkan hasil penelitian yang telah dilakukan, maka dapat disimpulkan bahwa kemampuan pemahaman konsep matematika siswa setelah diterapkannya Pendekatan Pendidikan Matematika Realistik Indonesia ( PMRI) di SMP PGRI Betung di kategorikan baik, hal ini ditunjukan dengan hasil nilai rata-rata tes akhir kemampuan pemahaman konsep matematika siswa adalah 76,8 .

\section{DAFTAR PUSTAKA}

Herawaty, D., \& Widada, W. (2018). The Influence of Contextual Learning Models and the Cognitive Conflict to Understand Mathematical Concepts and Problems Solving Abilities. https://doi.org/10.2991/icomse-17.2018.17

Herawaty, D., Widada, W., Nugroho, K. U. Z., \& Anggoro, A. F. D. (2019). The Improvement of the Understanding of Mathematical Concepts through the Implementation of Realistic Mathematics Learning and Ethnomathematics. https://doi.org/10.2991/icetep18.2019.6 
Ma'Rifah, N., Widada, W., Aida, A., Yulfitri, Y., \& Effendi, J. (2019). The students' mathematics understanding through ethnomathematics based on kejei dance. Journal of Physics: Conference $\quad$ Series. $\quad$ https://doi.org/10.1088/17426596/1318/1/012079

Nugroho, K. U. Z., Widada, W., Zamzaili, \& Herawaty, D. (2019). The ability to solve mathematical problems through youtube based ethnomathematics learning. International Journal of Scientific and Technology Research

Suharto, W. (2018). The Cognitive Structure of Students in Understanding Mathematical Concepts. Advances in Social Science, Education and Humanities Research, 295, 65

Trianto. (2010). Mendesain Model Pembelajaran Inovatif-Progresif. Jakarta: Kencana Prenada Media Group

Widada, W., Herawaty, D., \& Lubis, A. N. M. T. (2018). Realistic mathematics learning based on the ethnomathematics in Bengkulu to improve students' cognitive level. Journal of Physics: Conference $\quad$ Series. $\quad$ https://doi.org/10.1088/1742$6596 / 1088 / 1 / 012028$

Widada, W., Herawaty, D., Mundana, P., Agustina, M., Putri, F. R., \& Anggoro, A. F. D. (2019). The REACT strategy and discovery learning to improve mathematical problem solving ability. Journal of Physics: Conference Series. https://doi.org/10.1088/17426596/1318/1/012081

Yanuarti, E. (2016a). Analisis Sikap Kerjasama Siswa dalam Proses Pembelajaran Pendidikan Agama Islam melalui Cooperative Learning. Media Akademika, 31(4), 613

Yanuarti, E. (2016b). Pendidikan Islam Dalam Perspektif Filsafat Idealisme. BELAJEA: Jurnal Pendidikan Islam. https://doi.org/10.29240/BJPI.V1I2.108

Yanuarti, E. (2016c). STUDI KOMPARATIF PRESTASI SISWA (Mengikuti dan tidak Mengikuti Ekstrakurikuler ROHIS). $A L$ ISHLAH, Vol XIV 
Yanuarti, E. (2018). Pemikiran Pendidikan Ki. Hajar Dewantara dan Relevansinya Dengan Kurikulum 13. Jurnal Penelitian. https://doi.org/10.21043/jupe.v11i2.3489

Yustisia, P. (2010). Panduan Lengkap KTSP. Yogyakarta: Putstaka Yustia 
200 | Ramadhan dan Yanuarti: Kemampuan Pemahaman Konsep Matematika Siswa ... 